Ibn Al-Haitham Jour. for Pure \& Appl. Sci. 33 (2) 2020

Ibn Al Haitham Journal for Pure and Applied Science

Journal homepage: http://jih.uobaghdad.edu.iq/index.php/j/index

\title{
Spectrophotometric Method for the Estimation of Ceftriaxone in Pure Form and Pharmaceuticals
}

\author{
Aya W. Ahmed \\ Salam A.H. Al-Ameri \\ Department of Chemistry, College of Science, University of Mustansiriyah \\ Ayawaleed47@yahoo.com \\ Article history: Received 17 June 2019, Accepted 6 August 2019, Published in April \\ 2020.
}

Doi: 10.30526/33.2.2441

\begin{abstract}
Ceftriaxone sodium were one of the widely antibacterial drugs used. Azo dye derivatization of diazonium salt that formed via the reaction between ceftriaxone with hydrochloric acid and sodium nitrite was developed for the on-research drug analysis then coupling with each one 2,5dimethylphenol (2,5-DMP) and 4-tertbutylphenol (4-TBP) respectively in the alkaline media. The developed diazonium coupling methods include an optimization study. The results show a limit of detection and limit of quantification $0.482,0.284 \mu \mathrm{g} / \mathrm{mL}$, and 1.607, $0.945 \mu \mathrm{g} / \mathrm{mL}$ using 2,5-DMP and 4 -TBP reagents respectively. Moreover, the recovery $\%$ obtained was $100.89 \%$, and $103.37 \%$ at linear concentration range $3.0-50$, and $10-30 \mu \mathrm{g} / \mathrm{mL}$, with molar absorptivity of $4.377 \times 10^{3}$, $7.446 \times 10^{3} \mathrm{~L} . \mathrm{mol}^{-1} . \mathrm{cm}^{-1}$ using 2,5-DMP and 4-TBP reagents respectively. An acceptable accuracy represented by the relative standard deviation (RSD\%) was achieved of a 0.46 and 0.37 for 2,5-DMP and 4-TBP respectively. The proposed method was successfully used for the determination of ceftriaxone sodium in pure and in pharmaceuticals.
\end{abstract}

Keywords: Ceftriaxone; Azo dye; Coupling; Spectrophotometric; 2,5-dimethylphenol; 4-tertbutylphenol.

\section{Introduction}

Cephalosporins consist of two - incorporated rings system of beta-lactam and dihydrothiazine [1]. Ceftriaxone sodium (CFT) is one of the third generation cephalosporins and one of the most widely used antibiotics to treat both bacterial infections Gram positive and Gram negative [2, 3]. The molecular formula is $\mathrm{C}_{18} \mathrm{H}_{18} \mathrm{~N}_{8} \mathrm{O}_{7} \mathrm{~S}_{3}$, Scheme I. [4].

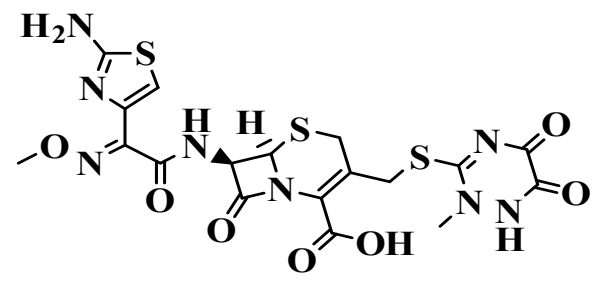

Scheme 1. Structure of Ceftriaxone Sodium. 
Ibn Al-Haitham Jour. for Pure \& Appl. Sci. 33 (2) 2020

Several analytical methods have been reported for the estimation of CFT in pure and pharmaceuticals such as spectrophotometric [5-8]. Spectrofluorimetry [9]. Infrared [10]. HPLC - UV [11-13]. Chromatography [14]. And HPLC- MS [15]. As well as in biological samples HPLC-UV [1620]. The idea of this work is to develop a simple, sensitive and effective method for the validation of the Ceftriaxone in pure and commercial preparation as a quality control purpose.

\section{Materials and Methods}

\section{2-1. Chemicals and Equipment:}

All chemicals used were of analytical reagent grade with high purity. Sodium nitrite, hydrochloric acid, potassium hydroxide, analytical standard of ceftriaxone sodium, analytical standard of 2,5-DMP and 4-TBP were purchased from Sigma-Aldrich, Al Qiffaf Scientific Company - Baghdad, Iraq. Double distilled water was used throughout the experiments for preparation of the reagents and samples.

For all absorbance detection, a double beam dual chopper, UV-Vis spectrophotometer, Varian, Cary 100, Australia was used pH S-3E Precision acidity Meter, Ray Magnetic Instrument Factory, Shanghai, China. Mettler AE 200 Electronic Balance, Germany and shaker.

\section{2-2. Preparation of a Ceftriaxone Sodium Stock Solution}

A $1000 \mu \mathrm{g} . \mathrm{mL}^{-1}$ of standard CFT was prepared by dissolving $0.1 \mathrm{~g}$ in $100 \mathrm{~mL}$ of distilled water then prepared a diluted solution.

\section{2-3. General Procedures:}

\section{2-3-1. Coupling the Ceftriaxone with the 2,5-DMP reagent:}

In an ice bath at zero to $5{ }^{\circ} \mathrm{C}$; in a $20 \mathrm{~mL}$ volumetric flasks take a $0.5 \mathrm{~mL}$ of $1000 \mu \mathrm{g}$. $\mathrm{mL}^{-1}$ of standard CFT solution then add $2.0 \mathrm{~mL}$ of $0.57 \mathrm{M} \mathrm{HCl}$ and $0.5 \mathrm{~mL}$ of $0.14 \mathrm{M} \mathrm{NaNO} 2$ which lead to forming a diazonium salt after leaving the solution for 10 minutes which coupling with $1.5 \mathrm{~mL}$ of $2.0 \mathrm{x}$ $10^{-3} \mathrm{M} 2,5$-DMP reagent in alkali media by using $1.5 \mathrm{~mL}$ of $0.45 \mathrm{M} \mathrm{KOH}$. The Azo dye formed was diluted with distilled water to the mark. The colored product solution was measured at $520 \mathrm{~nm}$.

\section{2-3-2. Coupling the Ceftriaxone with the 4-TBP Reagent:}

In an ice bath at zero to $5{ }^{\circ} \mathrm{C}$; in a $20 \mathrm{~mL}$, volumetric flasks a $0.5 \mathrm{~mL}$ of $1000 \mu \mathrm{g} . \mathrm{mL}^{-1}$ of standard CFT solution was taken then a1.5 $\mathrm{mL}$ of $0.57 \mathrm{M} \mathrm{HCl}$ and $1.0 \mathrm{~mL}$ of $0.14 \mathrm{M} \mathrm{NaNO}_{2}$ was added that led to form a diazonium salt after leaving the solution for 10 minutes which coupling with $1.5 \mathrm{~mL}$ of $2.5 \mathrm{x}$ $10^{-3} \mathrm{M} 4$-TBP reagent in alkali media by using $2.0 \mathrm{~mL}$ of $0.45 \mathrm{M} \mathrm{KOH}$. The Azo dye formed was diluted with distilled water to the mark. The product colored solution was measured at $500 \mathrm{~nm}$.

\section{Result and Discussion}

Initial tests were performed via the spectrophotometric method for the estimating of CFT by using 2,5-DMP and 4-TBP reagents and a red color of the azo dye formed was illustrate, Figure $1 \mathbf{A}, \mathbf{B}$. 
Ibn Al-Haitham Jour. for Pure \& Appl. Sci. 33 (2) 2020
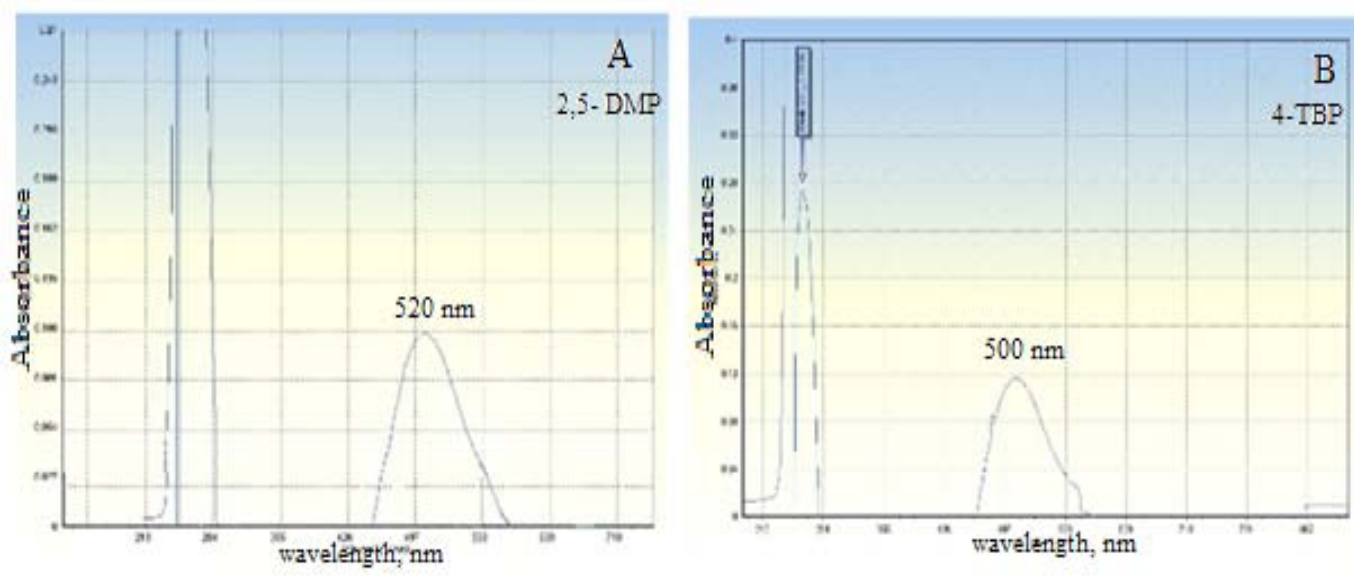

Figure 1. Initial UV-Vis spectra for CFT azo dye with (A) 2,5-DMP and (B) 4-TBP reagents.

\section{3-1. Method Optimization}

This spectrophotometric method for CFT estimation including diazonium coupling was optimized. The optimization parameters are; $\mathrm{HCl}$ and $\mathrm{NaNO}_{2}$ concentrations also the alkaline type and concentration.

\section{3-1-1. Hydrochloric acid volume}

The volume of hydrochloric acid that is important to the nitrous acid resulting with sodium nitrite which reacts with the amine group of ceftriaxone to form the diazonium salt.

The increase of acid volume was effect on the resulting azo dye absorbance. The optimum volume was 1.0 and $1.5 \mathrm{~mL}$ of $0.57 \mathrm{M} \mathrm{HCl}$ for 2,5-DMP and 4-TBP respectively, Figure 2. The intensity was reduced at higher or additional acid concentration which due to the incompetently converted of the primary amine [21].

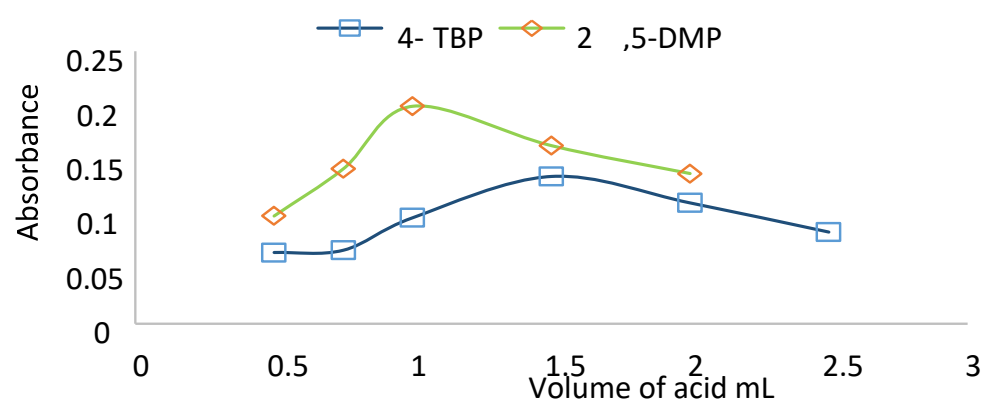

Figure 2. Effect of different $\mathrm{HCl}$ concentration (volume) on the CFT azo dye formation via 2,5-DMP and 4-TBP reagents.

\section{3-1-2. Sodium Nitrate Volume}

Sodium nitrate with $\mathrm{HCl}$ produced nitrous acid, which was responsible for the diazonium salt forming that was administered for the formation of azo dye. Increasing amounts of $0.14 \mathrm{M}$ sodium nitrate were studied in the range of $0.25-2.0 \mathrm{~mL}$. The best of the volume of sodium nitrate were 0.5 and $1.0 \mathrm{~mL}$ and the product dyes measured at $500 \mathrm{~nm}$ and $520 \mathrm{~nm}$ for 4-TBP and 2,5-DMP reagents respectively-as in Figure 3. The excess of the $\mathrm{NaNO}_{2}$ volume caused interferences contamination that led to reduce the absorbance [22]. 
Ibn Al-Haitham Jour. for Pure \& Appl. Sci. 33 (2) 2020

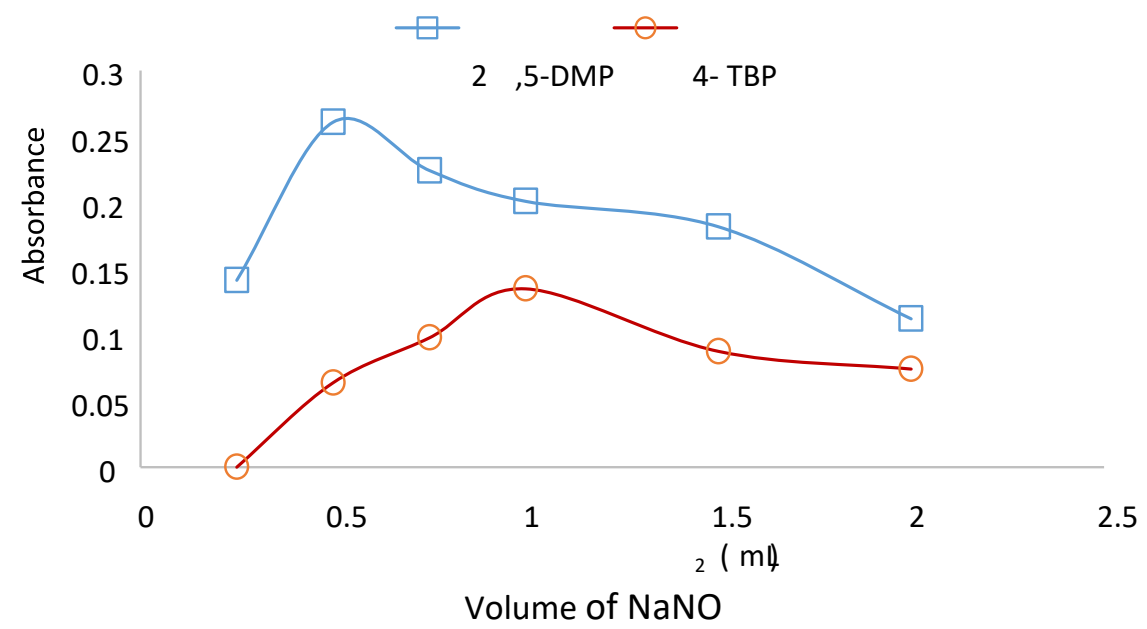

Figure 3. Effect of different $\mathrm{NaNO}_{2}$ concentration (volume) on the CFT azo dye formation via 2,5-DMP and 4-TBP

\section{3-1-3. Reaction Time} reagents.

The reaction time was studied over a period of zero to 30 minutes to discover the ideal time for the diazonium salts and the developed azo dyes affect the absorbance intensity. The results illustrated that the 10 minutes was a sufficient time-as in Figure 4.

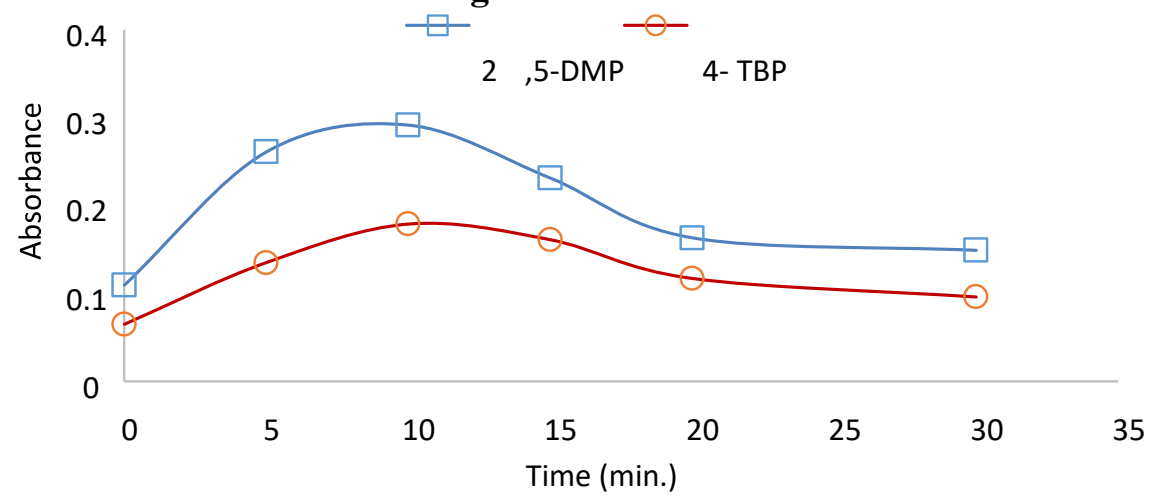

Figure 4. Effect of different reaction time on the CFT azo dye formation via 2,5-DMP and 4-TBP reagents.

\section{3-1-4. Base type and Concentration}

The alkaline media was so important to remove hydrogen atom of the phenolic compounds, which changed to very active species called phenoxide ion that coupling with diazonium salts to form azo dyes. A range of bases such as $\mathrm{NaOH}, \mathrm{KOH}, \mathrm{NH}_{4} \mathrm{OH}$ and $\mathrm{Na}_{2} \mathrm{CO}_{3}$ at the concentrations range of 0.23 , $0.35,0.45$ and $0.62 \mathrm{M}$. Potassium hydroxide was chosen as a best with 2,5-DMP and 4-TBP respectively as in Figure 5-A.

Additionally, optimum volume of $\mathrm{KOH}$ was studied in a range of $0.5-2.5 \mathrm{~mL}$ which showed that the 1.5 and $2.0 \mathrm{~mL}$ with 2,5-DMP and 4-TBP respectively were the appropriate volumes which gave a good dye with higher absorbance as in Figure 5-B. 

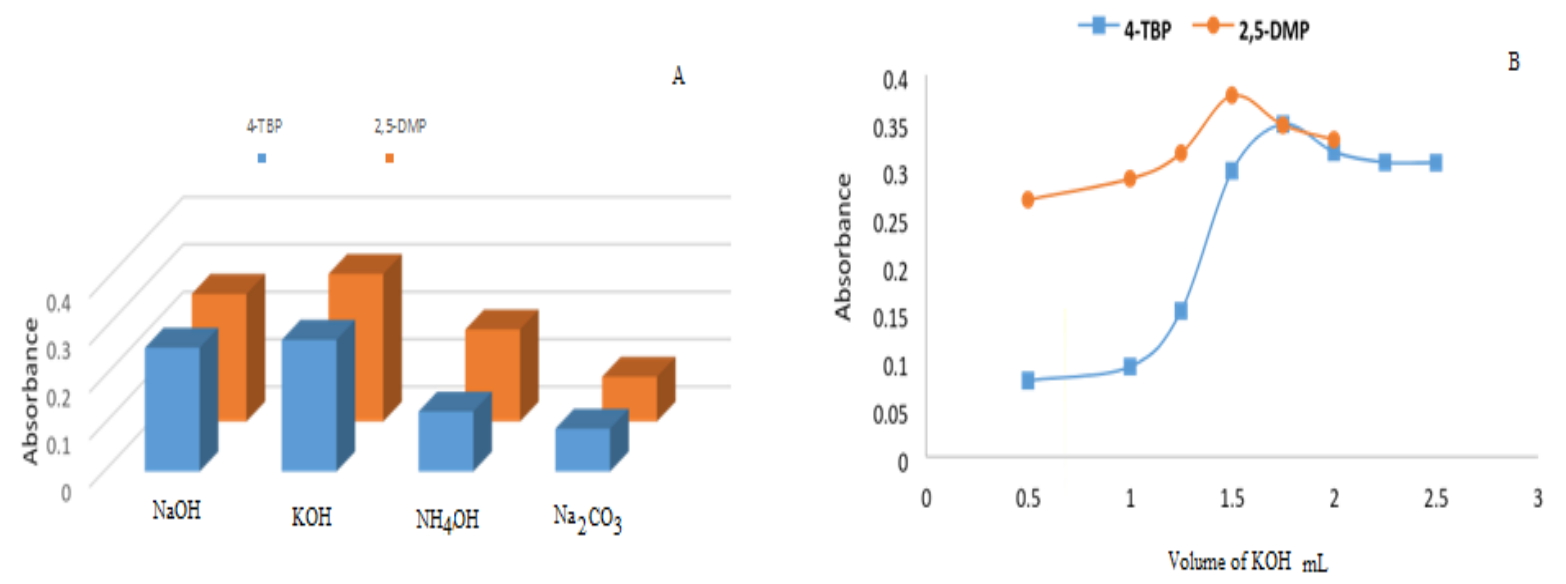

Figure 5. Effect of different alkaline types (A) and concentrations (B) on the CFT azo dye formation via 2,5-DMP and 4TBP reagents.

\section{3-1-5. Volume of the Reagents 2,5-DMP and 4-TBP}

Various volumes of $2.0 \times 10^{-3} \mathrm{M} 2,5$-DMP and $2.5 \times 10^{-3} \mathrm{M} 4$-TBP reagents were used to select the appropriate volume, which was combined with CFT diazonium salt to form a dark azo dye that gave a high intensity and higher absorbance. The results showed that the $1.5 \mathrm{~mL}$ of 2,5 -DMP and 4-TBP is the best volume, as in Figure 6.

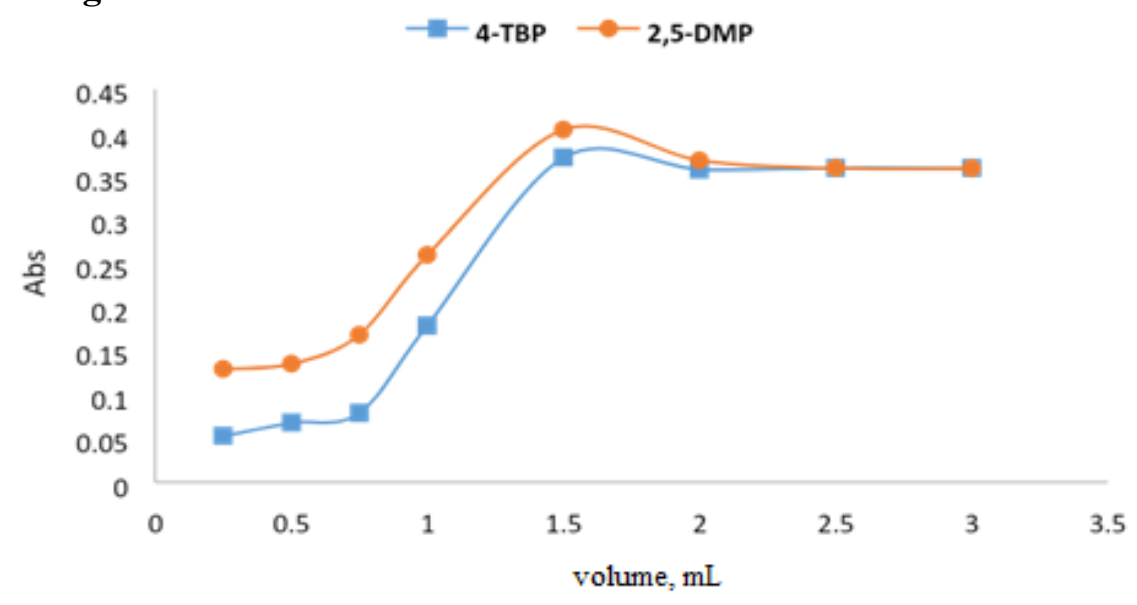

Figure 6. Effect of different 2,5-DMP and 4-TBP reagents on the CFT azo dye formation.

\section{3-2. Calibration Curve and Analytical Merits}

Calibration curves was constructed using $2.0 \times 10^{-3} \mathrm{M}$ 2,5-DMP and $2.5 \times 10^{-3} \mathrm{M}$ 4-TBP solutions with a concentration ranges of $3.0-50 \mu \mathrm{g}$. $\mathrm{mL}^{-1}$ and $10-30 \mu \mathrm{g} . \mathrm{mL}^{-1}$ of CFT solution via 2,5-DMP and 4-TBP respectively versus the absorbance resulted, as in Figure 7. The absorbance spectra were measured at $\lambda \max$ of $520 \mathrm{~nm}$ and $500 \mathrm{~nm}$ for CFT with 2,5-DMP and 4-TBP respectively, as in Figure 8.

All the analytical data such as limit of detection (LOD), limit of quantification (LOQ) and relative standard deviation (\%RSD) were summarized in Table 1. [21]. 
Ibn Al-Haitham Jour. for Pure \& Appl. Sci. 33 (2) 2020

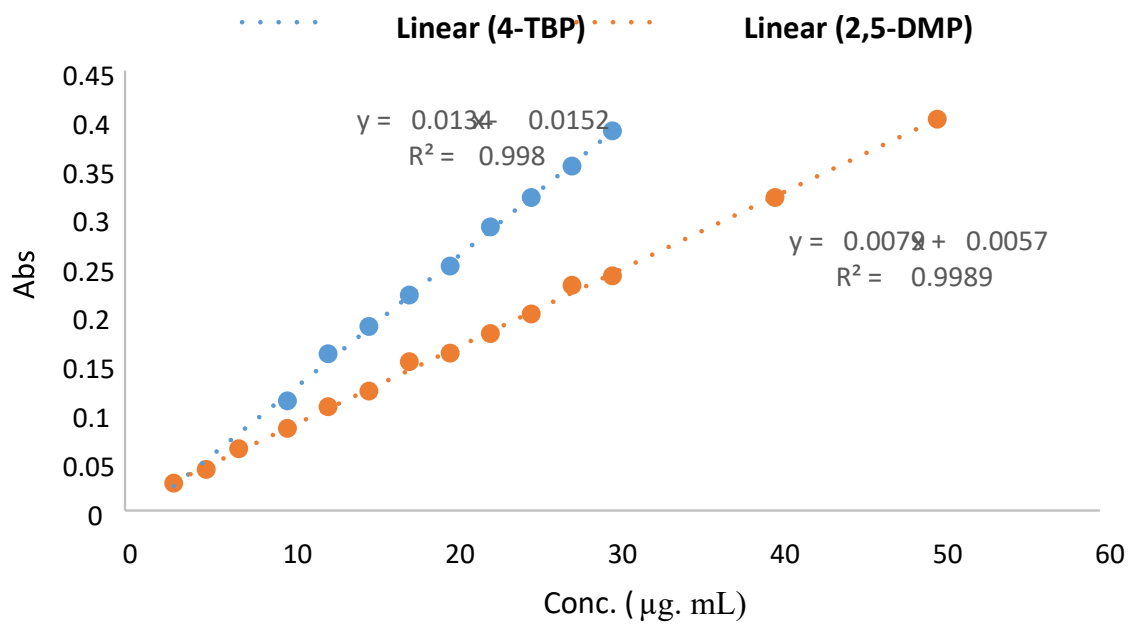

Figure 7. Calibration graph of $10-30$ and $3.0-50 \mu \mathrm{g}$. $\mathrm{mL}^{-1}$ of CFT with $2.0 \times 10^{-3} \mathrm{M} 2,5$-DMP and $2.5 \times 10^{-3} \mathrm{M} 4-\mathrm{TBP}$ respectively.
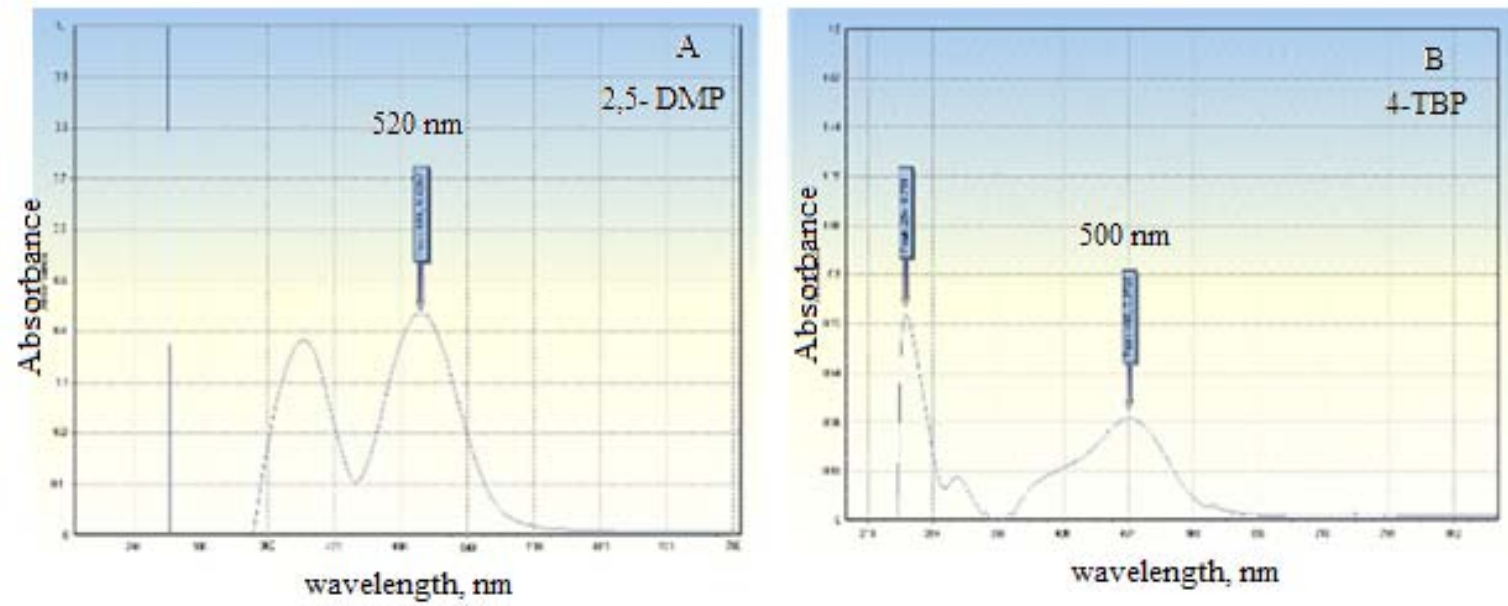

Figure 8. UV-Vis spectra of Calibration graph of $10-30$ and $3.0-50 \mu \mathrm{g} . \mathrm{mL}^{-1}$ of CFT with $2.0 \times 10^{-3} \mathrm{M} 2,5-\mathrm{DMP}$ and 2.5 x $10^{-3} \mathrm{M}$ 4-TBP respectively. 
Ibn Al-Haitham Jour. for Pure \& Appl. Sci. 33 (2) 2020

Table 1. Analytical data of the proposed diazotization-coupling methods.

\begin{tabular}{|l|c|c|}
\hline \multicolumn{1}{|c|}{ Parameters } & $2,5-\mathrm{DMP}$ & 4 -TBP \\
\hline Color & red & Orange \\
\hline$\Lambda \mathrm{max}, \mathrm{nm}$ & 520 & 500 \\
\hline Linearity range, $\mu \mathrm{g} . \mathrm{mL}^{-1}$ & $(3-50)$ & $(10-30)$ \\
\hline Molar absorptivity, $\varepsilon, \mathrm{L} . \mathrm{mol}^{-1} \cdot \mathrm{cm}^{-1}$ & $4.377 \times 10^{3}$ & $7.446 \times 10^{3}$ \\
\hline Slope, $\mathrm{b}$ & 0.0079 & 0.0134 \\
\hline Intercept, a & 0.0057 & -0.0152 \\
\hline Sandal sensitivity, S & 0.1267 & 0.0745 \\
\hline coefficient of determination, $\% \mathrm{R}^{2}$ & 99.89 & 99.8 \\
\hline correlation coefficient, $\mathrm{r})$ & 0.9994 & 0.9990 \\
\hline limit of detection, $\mathrm{LOD}, \mu \mathrm{g} \cdot \mathrm{mL}^{-1}$ & 0.4820 & 0.2840 \\
\hline Limit of quantification, $\mathrm{LOQ}, \mu \mathrm{g} \cdot \mathrm{mL}^{-1}$ & 1.6080 & 0.9454 \\
\hline
\end{tabular}

At a linear concentration range between $3.0-50$ and $10-30 \mu \mathrm{g} . \mathrm{mL}^{-1}$, the results showed a limit of detection and a limit of quantification of $0.482,0.284$ and $1.608,0.945 \mu \mathrm{g}$. $\mathrm{mL}^{-1}$ with 2,5 -DMP and 4TBP respectively with recovery of $100.89 \%$ and $103.37 \%$, with molar absorptivity of $4.377 \times 10^{3}$ and $7.446 \times 10^{3} \mathrm{~L} . \mathrm{mol}^{-1} \cdot \mathrm{cm}^{-1}$ for 2,5-DMP and 4-TBP respectively.

\section{3-3. Accuracy and Precision}

The precision and accuracy were calculated by the analysis a five replicates for three different CFT concentrations [21]. The precision was estimation by the determine of percent relative error \%R.E whereas the accuracy was determination by calculating the percent relative standard deviation \%RSD. An reasonable precision with acceptable accuracy was obtained which illustrated a 0.46 and 0.37 for 2,5-DMP and 4-TBP as in Table 2.

Table 2. The accuracy and precision of the developed method with 2,5-DMP and 4-TBP reagents.

\begin{tabular}{|c|c|c|c|c|c|c|}
\hline Type of reagent & $\begin{array}{c}\text { Conc. Taken, } \\
\mu \mathrm{g} . \mathrm{mL}^{-1}\end{array}$ & $\begin{array}{c}\text { Conc. Found } \\
\mu \mathrm{g} . \mathrm{mL}^{-1}\end{array}$ & $\begin{array}{c}\text { Relative } \\
\text { Error\% }\end{array}$ & \%RSD & $\begin{array}{c}\text { *Recovery, } \\
\%\end{array}$ & $\begin{array}{c}* * \text { Average } \\
\text { Recovery }\end{array}$ \\
\hline \multirow{2}{*}{2,5 -DMP } & 1.0 & 0.98 & -2.0 & 0.46 & 98.0 & 100.89 \\
\cline { 2 - 6 } & 3.0 & 3.08 & 2.7 & & 102.7 & \\
\hline \multirow{2}{*}{$4-\mathrm{TBP}$} & 5.0 & 5.1 & 2.0 & & 102.0 & \multirow{2}{*}{103.378} \\
& 1.0 & 1.09 & 9.0 & 0.37 & 109.0 & \\
\hline
\end{tabular}

* Average for 5 determinations. ** Average for 15 determinations. 
Ibn Al-Haitham Jour. for Pure \& Appl. Sci. 33 (2) 2020

\section{3-4. CFT: Reagent Stoichiometry}

A continuous variation (Job) method [22]. Was applied for the estimation of CFT: reagent stoichiometry. The solutions were prepared at an equal concentration of $2.0 \times 10^{-3} \mathrm{M}$ for CFT with 2.5DMP and $2.5 \times 10^{-3} \mathrm{M}$ for CFT and 4-TBP. This method was applied by increasing the volumes from 0.1 to $0.9 \mathrm{~mL}$ of CFT and reducing the volumes from 0.9 to $0.1 \mathrm{~mL}$ of reagents to a final volume of 1.0 $\mathrm{ml}$. The results showed a conjugated ratio is of 1:1 between CFT with two reagents, Figure 9, 10.
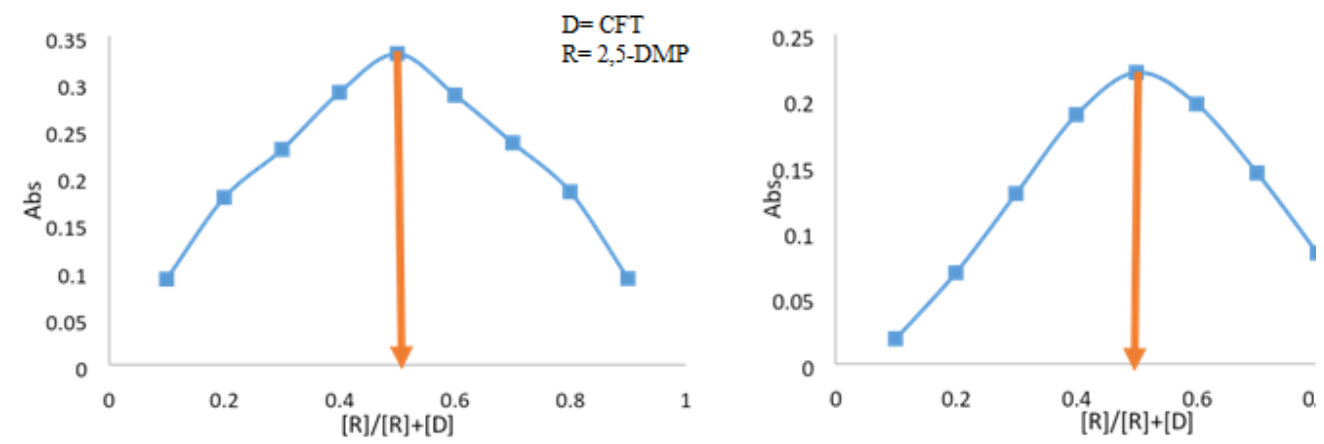

Figure 9. Continuous variation method for CFT: Reagent stoichometry with 2,5-DMP at 520nm and with 4-TBP at $500 \mathrm{~nm}$.

\section{3-5. Application of the developed method for the CFT estimation in pharmaceuticals}

This developed method was successfully used for the CFT determine in commercial pharmaceuticals for diverse products from Malaysia, Jordan and United Arab of Emirate at a concentration of 6.0 and 10 $\mu$ g. $\mathrm{mL}^{-1}$. The results were summarized in Tables 3, 4 .

Table 3. Assay of CFT in pharmaceutical preparations using 2,5-DMP reagent

\begin{tabular}{|c|c|c|c|c|c|}
\hline \multirow{2}{*}{$\begin{array}{c}\text { pharmaceuticals } \\
\text { of CFT }\end{array}$} & $\begin{array}{c}\text { Conc. Taken } \\
\mu \mathrm{g} . \mathrm{mL}^{-1}\end{array}$ & $\begin{array}{c}\text { Conc.Found } \\
\mu \mathrm{g} . \mathrm{mL}^{-1}\end{array}$ & $\% \mathrm{RE}$ & $\begin{array}{c}* \text { Recovery } \\
\%\end{array}$ & $\begin{array}{c}* * \text { Average } \\
\text { Recovery }\end{array}$ \\
\hline \multirow{2}{*}{ Malaysia } & 6.0 & 6.002 & 0.03 & 100.03 & 100.57 \\
\cline { 2 - 5 } & 10 & 10.11 & 1.1 & 101.1 & 101.99 \\
\hline \multirow{2}{*}{ Jordan } & 6.0 & 6.1 & 1.67 & 101.67 & 102.3 \\
\hline \multirow{2}{*}{ United State Emirate } & 10 & 10.23 & 2.3 & 98.28 & 99.14 \\
\cline { 2 - 5 } & 6.0 & 5.897 & -1.72 & 99.99 & \\
\hline
\end{tabular}

* Average for 5 determinations, ** Average for 10 determinations for two concentration.

Table 4. Assay of CFT in pharmaceutical preparations using 4-TBP reagent.

\begin{tabular}{|c|c|c|c|c|c|}
\hline pharmaceuticals of CFT & $\begin{array}{c}\text { Conc. Taken } \\
\mu \mathrm{g} . \mathrm{mL}^{-1}\end{array}$ & $\begin{array}{c}\text { Conc. Found } \\
\mu \mathrm{g} . \mathrm{mL}^{-1}\end{array}$ & $\% \mathrm{RE}$ & $\begin{array}{c}* \text { Recovery } \\
\%\end{array}$ & $\begin{array}{c}* * \text { Average } \\
\text { Recovery }\end{array}$ \\
\hline Malaysia & 6.0 & 6.011 & 0.18 & 100.18 & 101.39 \\
\hline \multirow{2}{*}{ Jordan } & 10 & 10.26 & 2.6 & 102.6 & 104.7 \\
\hline United State Emirate & 6.0 & 6.32 & 5.3 & 105.3 & 104.1 \\
\hline
\end{tabular}

* Average for 5 determinations. ** Average for 10 determinations for two concentration. 
Ibn Al-Haitham Jour. for Pure \& Appl. Sci. 33 (2) 2020

\section{Conclusion}

This study is successfully employed for the CFT determination in pharmaceuticals, which gave an increase in the analytical sensitivity, selectivity and precision. The procedure in spectral mode was simple, inexpensive and accurate.

\section{Acknowledgement}

Authors are so grateful to Dr. Ammer S. Mahdi, College of Science, Mustansiriya University, Chemistry department for his hard helpful during this work.

\section{References}

1. Shahbaz, K.J.P.; Evaluations, B. Cephalosporins: pharmacology and chemistry. pharmaceutical and biological evaluations.2017, 4, 6, 234-238.

2. Zeng, L.; Hu, D.; Choonara, I.; Mu, D.; Zhang, L.; Li.X.; Zhang, Z.; Hu, Z.; Quan, S. A prospective study of the use of antibiotics in the Emergency Department of a Chinese University Hospital. International Journal of Pharmacy Practice.2017, 25, 1, 89-92.

3. Ivády, B.; Kenesei, É.; Tóth-Heyn, P.; Kertész, G.; Tárkányi, K.; Kassa, C.; Ujhelyi, E.; Mikos, B.; Sápi, E.; Varga-Heier, K.J.I. Factors influencing antimicrobial resistance and outcome of Gram-negative bloodstream infections in children. A Journal of Infectious Diseases.2016, 44, 3, 309-321.

4. Okorie, O.; Abayomi, E.O.; Onyinyechi, E. J. J. o. P. R. I. Pharmaceutical Quality Analysis of Ceftriaxone Sodium Brands Marketed in Southern Nigeria. Journal of Pharmaceutical Research International.2016, 1-8.

5. Sajjad, A.I.; Naresh, M.I.; Jasmin, K.; Rasul Jan, S.M.; Zohra, K.; Muhammad, A. Development of spectrophotometric method for determination of ceftriaxone sodium in different brands of pharmaceutical preparation involving diazotization, International J. of Pharmaceutical Sciences and Research.2015, 6,12.

6. Rind, F.M.A.; Memon1, M.G.H.L.; Mughal, A.H.; Almani1, U.R.; Memon1, F.; Khuhawar N.; Maheshwari, M.Y. Spectrophotometric Determination of Ceftriaxone Using 4Dimethylaminobenzaldehyde, Pak. J. Anal. Environ. Chem.2008, 9, 1, 43 - 48.

7. Lakshmi, K.S.; Nithya Mathi, K.I.N.; Balaji, S.; Kibe Victor Wathugi, D.; Satish, A.V. Visible Spectrophotometric Determination of Ceftriaxone Sodium in Vials , Asian J. of Chemistry.2007, 19, 4, 2517-2520.

8. Patel*, S.A.N.M.P.a.M. M. P. Spectrophotometric estimation of cefotaxime and ceftriaxone in pharmaceutical dosage forms, Indian J Pharm Sci.2006, 68, 1, 101-103.

9. Shah, J.; Jan, M.R.; Shah, S.J.L. Development and validation of a spectrofluorimetric method for the quantification of ceftriaxone in pharmaceutical formulations and plasma. Journal of Biological and Chemical Luminescence.2013, 28, 4, 516-522.

10. Trindade, M.; Salgado, H.J.P.C. Development and validation of a modern and stabilityindicating method for the quantification of ceftriaxona sodium in powder for injection by infrared spectroscopy. Physical Chemistry.2017, 7, 55-62.

11. Naguib, I.A.; Abdelaleem, E.A.; Zaazaa, H.E.; Hussein, E.A.E.J.E.J.o.C. Development and validation of stability indicating spectrophotometric and HPTLC methods for determination of acemetacin. European Journal of Chemistry.2014, 5, 2, 219-226.

12. El-Adl, S.M.; El-Shanawany, A.A.; Abdel-Aziz, L.M.; Hassan, A.F.J. A.J.o.P.A. HPLC Determination of Three Cephalosporins (Cefepime, Cefotriaxone and Cefotaxime) in Their Bulk and Dosage Forms. Asian Journal of Pharmaceutical Analysis.2014, 4, 3, 91-97. 
13. Panchal, V.J.; Desai, H.T.; Dave, A.G.J.I.J.P.S. R. Development and Validation of Stability Indicating Method for Simultaneous Estimation of Ceftriaxone and Tazobactam Injection Using RP-UPLC Method. INTERNATIONAL JOURNAL OF PHARMACEUTICAL SCIENCES AND RESEARCH. 2014, 5, 2398-2405.

14. Page-Sharp, M.N.T.; Salman, S.; Moore, B.R.; Batty, K.T.; Davis, T.M.; Manning, L.J. A. a. chemotherapy. Validation and application of a dried blood spot ceftriaxone assay. 2016, 60, 1 , 14.

15. Tange, M.Y., M.; Nakai, Y.; Uchida, T.J.C.; Bulletin, P. The role of an impurity in ceftriaxone sodium preparation for injection in determining compatibility with calcium-containing solutions. 2016, 64, 3, 207.

16. Gergs, U.; Clauss, T.; Ihlefeld, D.; Weiss, M.; Pönicke, K.; Hofmann, G.O.; Neumann, J.J.J.o.P. Pharmacology, Pharmacokinetics of ceftriaxone in plasma and bone of patients undergoing hip or knee surgery. Journal of Pharmacy and Pharmacology. 2014, 66, 11, 15521558.

17. Kratzer, A.; Liebchen, U.; Schleibinger, M.; Kees, M.G.; Kees, F.J.J.o.C.B. Determination of free vancomycin, ceftriaxone, cefazolin and ertapenem in plasma by ultrafiltration: impact of experimental conditions. Journal of Chromatography B. 2014, 961, 97-102.

18. Shah, J.; Rasul Jan, M.; Shah, S.; Naeem Khan, M.J.J.o.t.M.C.S. Development and validation of HPLC method for simultaneous determination of ceftriaxone and cefaclor in commercial formulations and biological samples. Journal of the Mexican Chemical Society. 2013, 57, 4, 314-320.

19. Sun, H.; Wang, H.; Ge, X.J.J.o.c. 1.a. Simultaneous determination of the combined drugs of ceftriaxone sodium, metronidazole, and levofloxacin in human urine by high-performance liquid chromatography. Journal of Clinical Laboratory Analysis. 2012, 26, 6, 486-492.

20. Briscoe, S.E.; McWhinney, B.C.; Lipman, J.; Roberts, J.A.; Ungerer, J.P.J.J.o.C.B. A method for determining the free (unbound) concentration of ten beta-lactam antibiotics in human plasma using high performance liquid chromatography with ultraviolet detection. Journal of Chromatography B. 2012, 907, 178-184.

21. James N.M.; Jane, C.M. Statistics and chemometrics for analytical chemistry, P. E. L., Prentice Hall, 5th Ed. 2005.

22. Renny, J.S.; Tomasevich, L.L.; Tallmadge, E.H.; Collum, D.B.J.A.C.I.E. Method of continuous variations: applications of job plots to the study of molecular associations in organometallic chemistry. journal of the German Chemical Society.2013, 52, 46, 11998-12013. 